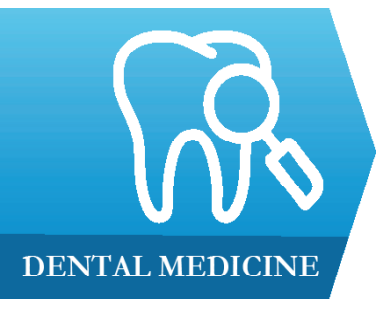

1) Discipline of Odontology, 2nd Department, Faculty of Dental Medicine, Iuliu Hatieganu University Napoca, Romania

2) Department of Polymeric Composites, "Raluca Ripan" Institute Bolyai University, Cluj-Napoca, Romania

3) Discipline of Prosthodontics, $4^{\text {th }}$ Department, Faculty of Dental Medicine, Iuliu Hatieganu University of Medicine and Pharmacy, ClujNapoca, Romania

All authors have equal contributions to Endodontics and Oral Pathology, of Medicine and Pharmacy, Clujfor Research in Chemistry, Babeșthis study.

\section{Comparative apical sealing evaluation of two bioceramic endodontic sealers}

Radu Chisnoiu ${ }^{1}$, Marioara Moldovan², Andrea Chisnoiu³, Dana Hrab Doina Rotaru ${ }^{1}$, Ovidiu Păstrav ${ }^{1}$, Ada Delean ${ }^{1}$

\begin{abstract}
Aim. The current study aims to evaluate, using scanning electronic microscopy, the sealing ability of two bioceramic endodontic sealers, one consecrated and one experimental.

Methods. Twenty monoradicular teeth were included in the study. The teeth were endodontically prepared at the working length. The shaping and cleaning involved the use of chelating gel MM EDTA $19 \%$ and continuous irrigation with sodium hypochlorite $2.5 \%$. The radicular filling was performed using gutta-percha in association with a sealer. Ten teeth were filled with consecrated endodontic filling material and the others ten with the experimental bioceramic based sealer.

Results. The evaluation of the sealers using SEM analysis allowed the identification and the measurement of gaps on the radicular dentin/sealer interface and the degree of apical sealing ability. No significant statistical difference was observed between the gap dimensions in the three areas for the tested bioceramic materials $(\mathrm{p}<0.005)$. In the apical region a homogenous layer with extensions intersecting the hybrid layer was observed when the experimental bioceramic sealer was used. In case of teeth filled with commercial sealer, peripheral hybrid extended areas were identified.
\end{abstract}

Conclusions. The two bioceramic sealers presented similar apical sealing. Gaps were identified in both sealers but also the presence of hybrid layer was identified.

Keywords: endodontic filling material, bioceramics, sealing ability, scanning electronic microscopy

\section{Background and aim}

Endodontic treatment without any or with an inappropriate radicular filling is named incomplete root canal treatment. Ingle et al. [1] have radiological evaluated the success of the endodontic treatment, noticing that $58 \%$ of all failures were caused by incomplete root canal filling. The main objective of endodontic therapy is to realize a tridimensional filling, in order to seal all communication to the apical area between the root canal and the periodontal space and to prevent bacterial penetration and reinfection with bacterial toxins [1].

Factors depending on sealing

Manuscript received: 03.07.2019

Received in revised form: 16.09 .2019

Address for correspondence: maria.chisnoiu@umfcluj.ro material characteristics represent a failure source, because of microleakage that might arise in sealer/dentin interface off sealer/filling core [2,3]. Adhesive luting of the sealer to radicular dentin and Accepted: 16.10.2019 monobloc formation might eliminate this inconvenient.

The ideal endodontic filling material should respect all these conditions. Improved adaptation of the apical seal can be achieved by creating a chemical bond between the sealant and the dentinal wall of the root canal and / or the slight expansion of the seal during the setting.

Sealing materials should also have antibacterial properties and not dissolve in fluids from the oral cavity. A group of materials meeting these desiderata are those in the bioceramic category.

Bioceramic based endodontic sealers (Endosequence BC, Total Fill BC) have been introduced recently in clinical dental practice, containing zirconiaoxid, calcium silicate, calcium monobasic phosphate, calcium hydroxide and 
various filling and thickening agents. These materials are usually available in calibrated syringe with mixing tips. They present hydrophilic properties, using intracanalar moisture to complete the setting reaction and are setting contraction free.

Controversial results have been reported in the literature regarding the relation between apical marginal fit and sealing ability of endodontic materials. Some authors consider there is no correlation between sealing in the apical area and the properties of filling materials ${ }^{4}$, while other sustain the contrary [4]. However, considering the controversial outcomes and limitations, it appears that evaluating the apical marginal adaptation of the filling materials, i.e. the ratio of radicular dentinal walls, can provide valuable information about the apical sealing capacity of these materials [5].

The apical sealing ability of different sealers can be assessed by various methods: antibacterial effect, fluid penetration method, microinfiltration evaluation, or use of electronic scanning microscopy (SEM) [6].

One of the first and most commonly used methods in the study of the mechanisms involved in the adhesion process is Scanning Electron Microscopy (SEM). The SEM principle is based on the pseudo-tridimensional image, which is built point-to-line with line-based secondary electrons [7].

The current study aims to evaluate, using SEM, the sealing ability of two bioceramic endodontic sealers, a consecrated one (TotalFill BC, FKG Swiss Endo) and an experimental one, developed in collaboration with "Raluca Ripan" Institute for Research in Chemistry, ClujNapoca.

\section{Methods}

Twenty monoradicular teeth (lower premolars) were included in the present study. The teeth were extracted for orthodontic or periodontal reasons 4 weeks before starting this experiment. The teeth that had internal root resorption, calcifications, previous endodontic treatments or teeth that have been identified with more than one canal per root, were removed from the study. For the batch uniformity, digital x-rays in two different angles were performed.

The teeth were coronary sectioned in order to obtain a $16 \mathrm{~mm}$ working length, identical in the whole studied group using a diamond disc attached to the straight hand piece.

The working length was determined visually by introducing a K-file instrument into the root canal (ISO $M M ®$ diameter $10 / 100 \mathrm{~mm}$ ), until the tip was visible at the apex. The working length was determined by withdrawing the instrument for $0.5 \mathrm{~mm}$ [8].

Teeth preparation

a. Mechanical-antiseptic preparation of the root canals. The teeth were prepared by a single operator at working length using ProTaper ${ }^{\circledR}$ system (Dentsply Maillefer) and X - SmartTM endodontic micromotor Motor $\AA$ (Dentsply, UK) in continuous rotation until F2 (size $0.25 \mathrm{~mm}$; taper $8 \%$ ) instrument at the speed of $250 \mathrm{rpm}$ (revolutions per minute), according to the manufacturer's instructions.

The mechanical and antiseptic treatment involved the use of a chelating gel, ethylenediaminetetraacetic acid, MM EDTA ${ }^{\circledR}$ (Micromega, France) on each of the endodontic preparation instrument and continuous irrigation with sodium hypochlorite concentration of $2.5 \%$ ( $5 \mathrm{ml}$ per sample), as used in previous in vitro studies $[9,10]$. At the end of the preparation, the root canal was irrigated with $2 \mathrm{ml}$ EDTA $17 \%$ concentration, maintained for 3 minutes in order to remove the smear layer. The canals were dried using paper points adjusted at the working length.

b. The root canals obturation. The sample of 20 teeth was randomly divided into two groups $(\mathrm{n}=10)$. Each tooth of these groups was endodontically obturated using gutta-percha in combination with an experimental hydroxyapatite based sealer and one consecrated sealer - TotalFill BC (FKG Swiss Endo). The obturation technique used was warm vertical condensation technique in apical third and injection of gutta-percha in the coronal two-thirds. Warm vertical condensation technique represents one of the most appreciated techniques for root canal sealing. Therefore, the experimental material was designed to be used with this technique and, for comparison, the same technique was used for Total fill, according to the manufacturer's specifications which also describe this option $[11,12]$.

To allow the complete setting of the sealers, the teeth were preserved in a solution of sodium hypochlorite concentration of $2.5 \%, 100 \%$ humidity and a temperature of $37^{\circ} \mathrm{C}$ for 7 days. After the complete setting of the sealers, the samples were placed in distilled water for 10 minutes, rinsed with absolute ethanol for 15 minutes and then placed in an oven at a constant temperature of $37^{\circ} \mathrm{C}$ for 24 hours in order to dry them.

The samples, properly dried, were placed in resin blocks and left for 24 hours to complete the setting reaction of the resin. The resin blocks were sectioned using a microtome (Buehler-IsoMet 1000) in slices with $1 \mathrm{~mm}$ thickness.

Three samples from the apical third were selected for each tooth (apical, median and coronal).

\section{SEM evaluation}

All samples were analyzed using Scanning Electron Microscopy (Inspect F - FEI Company SUA). Using a 1000x magnification, the extent of the widest gap was measured (Figure 1).

Four points of measurement were chosen for each root slice, one in every quadrant. The mean value was recorded for each area. 
The measurements were performed using UTHSCSA Image Tool for Windows version 3.0, San Antonio, TX, USA (Figure 2).

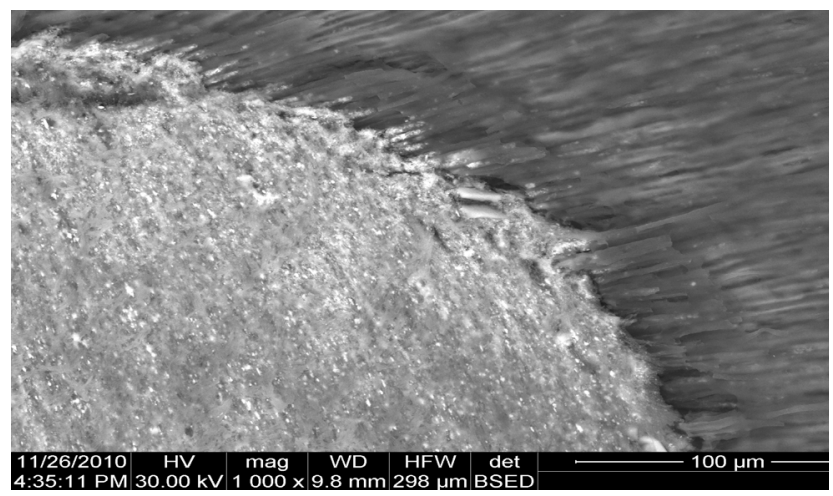

Figure 1. SEM image of root canal filling (experimental sealermagnification1000X).

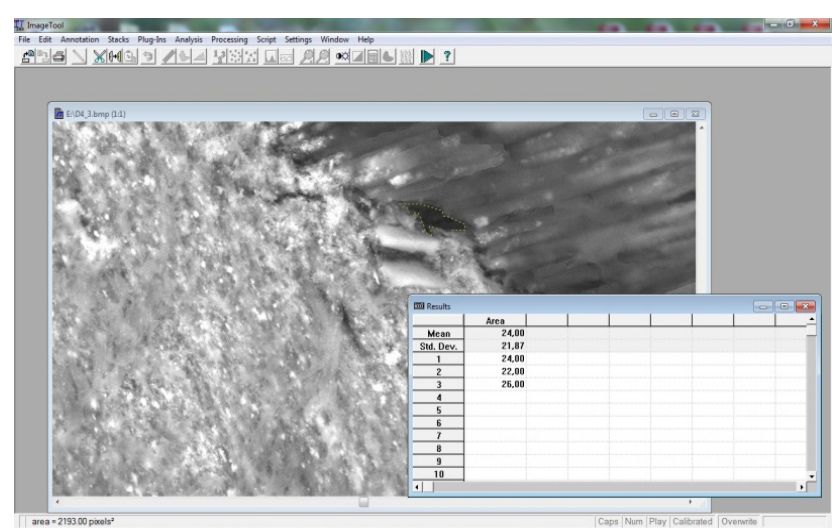

Figure 2. Gap measurement (experimental sealer) using UTHSCSA Image Tool for Windows version 3.0, San Antonio, TX, USA.
The data obtained from the measurements were statistically analyzed using the IBM SPSS Statistics software version 22.0. The one-way ANOVA test was used for the statistical analysis of the 3 levels studied and comparison between the 2 groups. A p value $<0.05$ was considered significant.

\section{Results}

Gap measurements, mean value (standard deviation) and statistical significance for each area are presented in table I. No significant statistical difference $(p>0.005)$ was observed between the gap dimensions in the three areas for the tested bioceramic materials.

Table I. Gap size, mean value ( $\mathrm{SD}=$ standard deviation) and statistical evaluation of study groups.

\begin{tabular}{ll|c|c} 
Area & Material & $\begin{array}{c}\text { Gap size } \\
\text { Mean }(\mu \mathrm{m}) \pm \text { SD }\end{array}$ & $\begin{array}{c}\text { P } \\
\text { (one way Anova) }\end{array}$ \\
\hline \multirow{2}{*}{ Apical } & TotalFill BC & $27.45 \pm 18.94$ & 0.71 \\
& Exp. Sealer & $24.04 \pm 26.92$ & \\
Median & TotalFill BC & $27.28 \pm 32.09$ & 0.525 \\
& Exp. Sealer & $28.73 \pm 17.02$ & \\
Coronal & TotalFill BC & $12.23 \pm 6.61$ & 0.466 \\
Apical, & Exp. Sealer & $19.21 \pm 8.25$ & \\
$\begin{array}{l}\text { median, } \\
\text { coronal }\end{array}$ & TotalFill BC & $22.32 \pm 20.17$ & 0.412 \\
& Exp. Sealer & $23.99 \pm 19.74$ & 0.624
\end{tabular}

SEM evaluation in case of the experimental sealer revealed the presence of a homogenous layer in the apical area with extensions intersecting the hybrid zone. An area with similar electronic density to the sealer area was observed in the hybrid zone (Figure 3).

In case of samples filled with TotalFill BC system, peripheral hybrid extended areas were identified (Figure 4).
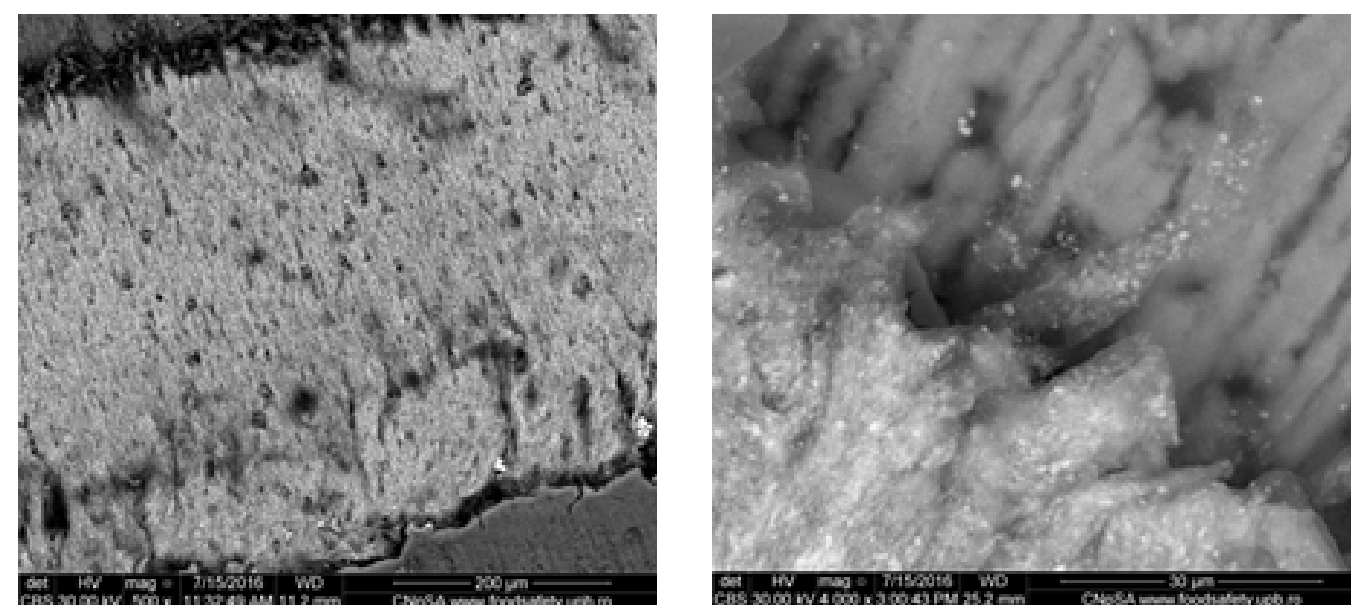

Figure 3. SEM images from experimental sealer/dentin interface in the apical area. 

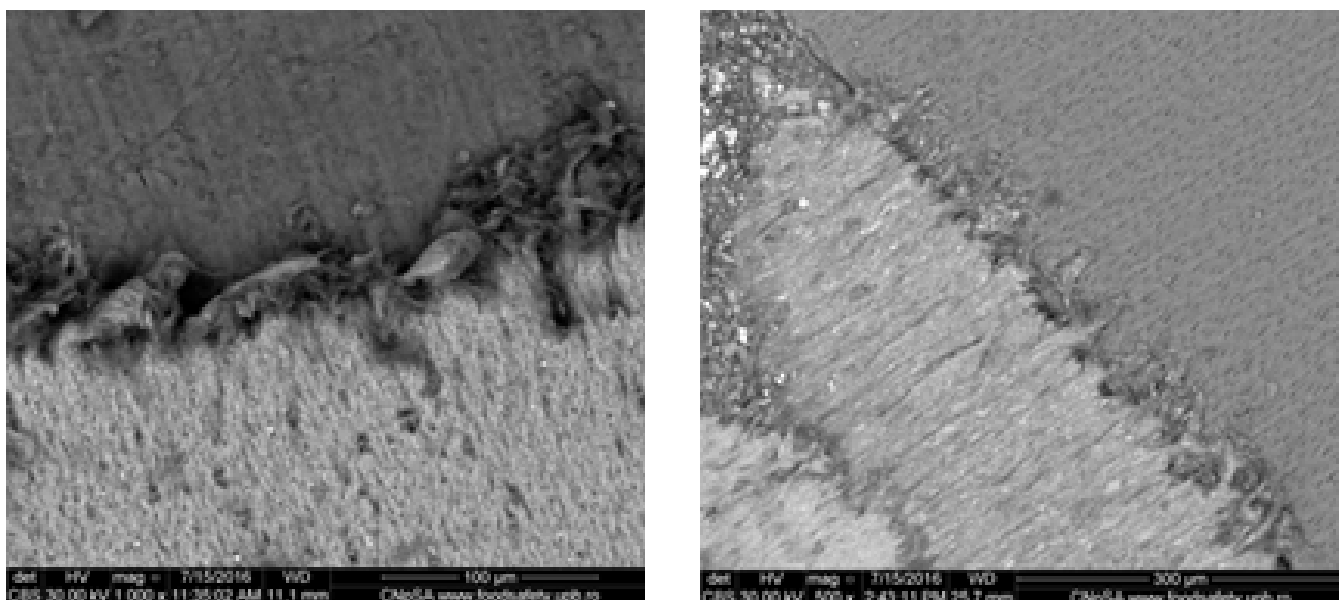

Figure 4. SEM images from eTotalFill BC sealer/dentin interface in the apical area.

\section{Discussion}

Various methods are available for apical sealing ability of endodontic filling materials such as: antibacterial effect, fluid penetration method, microleackage technique or scanning electron microscope. SEM analysis has been used in this study to evaluate the apical sealing of two bioceramic endodontic filling materials. The current study presents several limitations including the use of SEM analysis and the small number of teeth. SEM technique presents several disadvantages such as the bidimensional examination but also the potential separation of the filling material from the dentinal walls or fissure development into the hard dental tissue when high void (high vacum evaporation) technique is used during sample preparation. To overcome these limitations, some researchers (Torabinejad et al. [13]; Abdal and Retief [14]) have proposed the use of transverse sections, but contradictory results were obtained. They have attributed artificial gaps development to longitudinal segmentation. However, SEM examination is an appropriate method for assessing the marginal adaptation due to the high degree of magnification and the excellent resolution $[15,16]$.

During root canal preparation, smear layer results, containing organic, inorganic material, bacteria and bacterial products. It acts as a barrier between the filling materials and the root canal walls, thus compromising the formation of a satisfactory seal that can lead to the appearance of microinfiltrations $[17,18]$.

Various agents such as sodium hypochlorite, ethylenediaminetetraacetic acid (EDTA), mix tetracycline acid detergent (MTAD), organic acids (e.g., citric acid) have been introduced to remove the smear layer. Alternative use of EDTA and sodium hypochlorite has been recommended for the effective removal of the smear layer $[19,20]$. A chelating EDTA gel was used in our study for smear layer removal.

Shi et al. [21] compared the apical sealing ability of a bioceramic filling material (iRoot FS, innovative BioCeramix Inc., Vancouver, Canada) with that of MTA and found that samples filled with iRoot FS showed reduced microinfiltration compared to samples with MTA.

Ghattas et al. [22] have observed that EndoSequence $^{\mathrm{TM}}$ bioceramic endodontic obturation material has demonstrated a similar sealing capacity to that of aggregated trioxide (MTA) when used as a rootfilling material.

In the current study study, images obtained by SEM analysis have shown the presence of a hybrid layer in both sealers. The bioceramic sealers can penetrate into the dentinal tubules and polymerize, forming an hybrid layer. The formation of the hybrid layer is favoured by the existence of hydrophilic monomers and solvent in the bioceramic sealer composition [23].

By obtaining the hybrid layer, all communications between the exterior and the radicular canal are eliminated, realising a complete seal of the dentinal wound [24].

The new experimental sealer has a chemical composition, which favours the infiltration into the dentinal structure and the formation of the hybrid layer.

Failure of the formation of the hybrid layer will allow the communication between the endodontic space and periodontium and the appearance of marginal infiltration, favouring bacterial colonisation. At the same time water penetration is also possible, determining the hydrolytic degradation of the sealer and its connections with the dental structures [25].

The extensions of the sealer intersecting the hybrid layer present a similar electronic density with the overlying 
area, demonstrating a continuity of hydroxyapatite nanoparticles towards the depth.

The periphery of the radicular canals was also hybridized and the hybrid layer obtained using this material is extended in the entire depth of the area. In other words the sealer has mediated a complete adjustment between the dental structures and the gutta-percha [26].

The study of the interface between sealer and radicular dental walls has a significant clinical importance. The absence of adhesion between these interfaces may be associated with bacterial infiltration and therapeutic failure [27].

\section{Conclusions}

Within the limitations of the current study, we can conclude that the two bioceramic sealers presented similar apical sealing. Gaps were identified in both sealers, but the presence of hybrid layer was also identified. The preliminary results of this in vitro study suggest that the new experimental sealer presents good potential for practical application.

\section{References}

1. Ingle JI, Bakland LK, Baumgartner JC. $6^{\text {th }}$ ed. Hamilton: BC Decker Inc, Ingle's Endodontics; 2008: pp. 1053-1087.

2. Raina R, Loushine RJ, Weller RN, Tay FR, Pashley DH. Evaluation of the quality of the apical seal in Resilon/ Epiphany and Gutta-Percha/AH Plus-filled root canals by using a fluid filtrationn approach. J Endod. 2007;33:944947.

3. Drukteinis S, Peciuliene V, Maneliene R, Bendinskaite R. In vitro study of microbial leakage in roots filled with EndoREZ sealer/EndoREZ Points and AH Plus sealer/conventional gutta-percha points. Stomatologija. 2009;11:21-25.

4. Steier L, de Figueiredo JAP, Belli S. Comparison of the interface dentin-endodontic sealer using two SEM magnifications. Rev Odonto Ciênc. 2010;25:296-299.

5. Ravichandra P V R, Vemisetty H, K D, Reddy S J, D R., Krishna M JN, Malathi G. Comparative Evaluation of Marginal Adaptation of Biodentine ${ }^{\mathrm{TM}}$ and Other Commonly Used Root End Filling Materials-An Invitro study. J Clin Diagn Res. 2014;8:243-245.

6. Costa AT, Post LK, Xavier CB, Weber JB, Gerhardt-Oliveira M. Marginal adaptation and microleakage of five rootend filling materials: an in vitro study. Minerva Stomatol. 2008;57:295-300.

7. Costa AT, Konrath F, Dedavid B, Weber JB, de Oliveira MG. Marginal adaptation of root-end filling materials: an in vitro study with teeth and replicas. J Contemp Dent Pract. 2009; 10:75-82.

8. Robberecht L, Colard T, Claisse-Crinquette A. Qualitative evaluation of two endodontic obturation techniques: tapered single-cone method versus warm vertical condensation and injection system: an in vitro study. J Oral Sci. 2012;54:99104.
9. Mohammadian F, Farahanimastary F, Dibaji F, Kharazifard MJ. Scanning Electron Microscopic Evaluation of the Sealer-Dentine Interface of Three Sealers. Iran Endod J. 2017;12:38-42.

10. Collins J, Walker MP, Kulild J, Lee C. A comparison of three gutta-percha obturation techniques to replicate canal irregularities. J Endod. 2006;32:762-765.

11. Prodan D. Sinthesis and characterisation of new composite biomaterials used in dentistry - PhD Thesis. 2014: pp. 157205.

12. Elenjikal MJ, Latheef AA, Kader MAM, Ganapathy S, Mohamed AB, Sainudeen SS, et al. A Comparative Evaluation of Five Obturation Techniques in the Management of Simulated Internal Resorptive Cavities: An Ex Vivo Study. J Pharm Bioallied Sci. 2019;11(Suppl 2): S450-S456.

13. Torabinejad M, Smith PW, Kettering JD, Pitt Ford TR. Comparative investigation of marginal adaptation of mineral trioxide aggregate and other commonly used root-end filling materials. J Endod. 1995;21:295-299.

14. Abdal AK, Retief DH. The apical seal via the retrosurgical approach. I.A. preliminary study. Oral Surg Oral Med Oral Pathol. 1982;53:614-621.

15. Tay FR, Loushine RJ, Weller RN, Kimbrough WF, Pashley DH, Mak YF, et al. Ultrastructural evaluation of the apical seal in roots filled with a polycaprolactone-based root canal filling material. J Endod. 2005;31:514-519.

16. Van Meerbeeck B, Vargas M, Inoue S, Yoshida Y, Perdigão J, Lambrechts P, et al. Microscopy investigations. Techniques, results, limitations. Am J Dent. 2000;13(Spec No):3D-18D.

17. Torabinejad M, Higa RK, McKendry DJ, Pitt Ford TR. Dye leakage of four root end filling materials: effects of blood contamination. J Endod. 1994;20:159-163.

18. Shahi S, Yavari HR, Eskandarinezhad M, Kashani A, Rahimi S, Sadrhaghighi H. Comparative investigation of marginal adaptation of mineral trioxide aggregate (MTA) and Portland cement as root-end filling materials: A scanning electron microscopy (SEM) study. Afr J Biotechnol. 2011;10:1608416088. doi: 10.5897/AJB11.1860

19. Kuruvilla A, Jaganath BM, Krishnegowda SC, Ramachandra PK, Johns DA, Abraham A. A comparative evaluation of smear layer removal by using EDTA, Etidronic acid, and Maleic acid as root canal irrigants: An in vitro scanning electron microscopic study. J Conserv Dent. 2015;18:247-251.

20. Dechichi P, Christian C. Smear layer: A brief review of general concepts. Part II. The most common agents to remove endodontic smear layer. RFO UPF. 2006;11:100104.

21. Shi S, Zhang DD, Chen X, Bao ZF, Guo YJ. Apical sealing ability of bioceramic paste and mineral trioxide aggregate retrofillings: a dye leakage study. Iran Endod J. 2015;10:99103.

22. Nair U, Ghattas S, Saber M, Natera M, Walker C, Pileggi R. A comparative evaluation of the sealing ability of 2 root-end filling materials: An in vitro leakage study using Enterococcus faecalis. Oral Surg Oral Med Oral Pathol Oral Radiol Endod. 2011;112:e74-e77. 
23. Monticelli F, Osorio R, Mazzitelli C, Ferrari M, Toledano M. Limited decalcification/diffusion of self-adhesive cements into dentin. J Dent Res. 2008;87:974-979.

24. Al-Haddad A, Che Ab Aziz ZA. Bioceramic-Based Root Canal Sealers: AReview. Int J Biomater. 2016;2016:9753210.

25. Kaur A, Shah N, Logani A, Mishra N. Biotoxicity of commonly used root canal sealers: A meta-analysis. J Conserv Dent. 2015;18:83-88.
26. Shipper G, Teixeira FB, Arnold RR, Trope M. Periapical inflammation after coronal microbial inoculation of dog roots filled with gutta-percha and resilon. J Endod. 2005;31:91-96.

27. Karapinar-Kazandağ M, Tanalp J, Bayrak OF, Sunay H, Bayirli G. Microleackage of various root filling systems by glucose filtration analysis. Oral Surg Oral Med Oral Pathol Oral Radiol Endod. 2010;109:e96-e102. 